\title{
Off-Pump Coronary Artery Bypass (OPCAB) for Acute LMCA - LAD Dissection due to Blunt Chest Trauma: A Case Study
}

\author{
Gopal R', Nebhu MS', Mohamed AA ${ }^{3}$ and J alal \\ MJ A* \\ ${ }^{1}$ Department of Cardio-Thoracic and Vascular Surgery, \\ VPS Lakeshore Hospital, India \\ ${ }^{2}$ Department of Accident and Emergency Medicine, VPS \\ Lakeshore Hospital, India \\ ${ }^{3}$ Department of Internal Medicine and Rheumatology, \\ VPS Lakeshore Hospital, India \\ *Corresponding author: J alal MJA, Department of \\ Internal Medicine and Rheumatology, VPS Lakeshore \\ Hospital, India
}

Received: May 16, 2017; Accepted: June 16, 2017;

Published: J une 23, 2017

\section{Introduction}

Traumatic coronary artery dissection after blunt chest trauma is extremely rare [1]. It is usually associated with multiple organ traumas. Thrombolytic therapy, percutaneous intervention, and coronary artery bypass grafting are the various therapeutic options [2]. We describe a patient with acute coronary artery dissection after blunt chest trauma, which underwent Off-Pump Coronary Artery Bypass Grafting (OPCAB).

\section{Case Report}

A 55-year-old male presented with history of alleged road traffic accident (motorcycle versus motorcycle). He had history of loss of consciousness, retrograde amnesia, two episodes of vomiting and bleeding from the left nostril.

On examination, the patient had a Glasgow coma score of E4M6V5 with pupils bilaterally and equally reactive to light. He was hemodynamically stable with a blood pressure of $110 / 80 \mathrm{mmHg}$ and heart rate of 97 beats per minute. Heart sounds were regular, no murmurs. Chest was clear; but air entry was decreased on the left side. Abdomen was soft; no hepatosplenomegaly; non tender; bowel sounds present. No focal neurological deficits.

There was associated diffuse lung contusion; fracture thyroid lamina; fracture ribs including 1st rib; fracture right femur; fracture mandible and fracture left frontal and temporal bone, lateral wall of left orbit and left zygomatic arch.

CT brain (Figure 1) revealed Sub Dural Hemorrhage (SDH) in the left temporo-frontal region, maximum thickness of $11.5 \mathrm{~mm}$.

Electrocardiogram showed acute extensive anterior wall myocardial infarction. Echo-cardiogram revealed mildly dilated left ventricle; inter-ventricular septum, apex and anterior wall were a kinetic; Left Ventricular Ejection Fraction (LVEF) was 25\%; there was no pericardial effusion.
Coronary angiogram showed Acute Left Main Coronary Artery (LMCA)-Left Anterior Descending artery (LAD) dissection with Thrombolytic in Myocardial Infarction (TIMI) grade I-II flow from ostial LAD onwards, severe stenos is of mid LAD and mid Right Coronary Artery (RCA) (Figure 2).

In view of SDH and extensive limb, mandible \& Thyroid laminar injuries, anti-platelets were contraindicated. Hence, he was taken up for urgent Coronary Artery Bypass Grafting (CABG). Bilateral chest drains were inserted pre operatively due to thyroid laminar fracture keeping in view the possibility of a tension pneumothorax during induction of anesthesia. Patient underwent emergency off pump coronary artery bypass grafting. Due to severe hemodynamic instability and rib fracture, Left Internal Mammary Artery (LIMA) could not be harvested. Hence, only left saphenous vein was harvested (Figure 3a). Grafting with vein grafts were done to LAD and Diagonal (Figures $3 \mathrm{~b} \& 3 \mathrm{c}$ ). Even after the completion of grafting, patient remained hemodynamically unstable, needing high ionotropic supports. Contractility of LAD territory was poor. Urine output decreased. Hence Intra-Aortic Balloon Pump (IABP) was inserted. The patient became stable after IABP insertion. Hemostasis was achieved. He was shifted to the post cardiac surgery intensive care unit with IABP support and later was weaned of IABP by the second

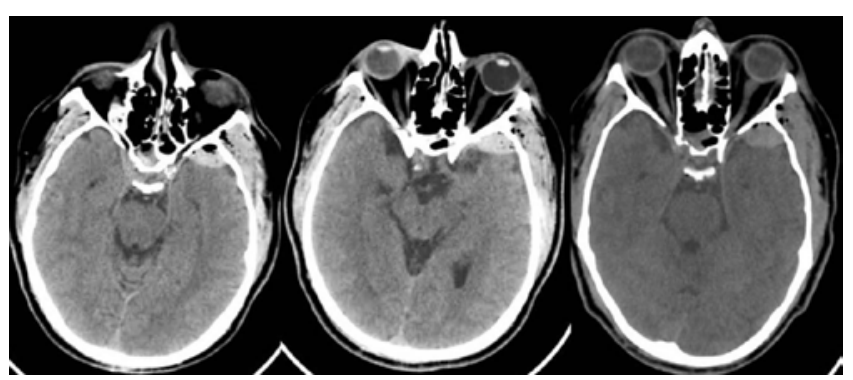

Figure 1: CT brain showing sub dural hemorrhagein the left temporo-frontal region.
Austin J Surg - Volume 4 Issue 2 - 2017

ISSN : 2381-9030 | www.austinpublishing group.com

Jalal et al. (C) All rights are reserved
Citation: Gopal R, Nebhu MS, Mohamed AA and Jalal MJA. Off-Pump Coronary Artery Bypass (OPCAB) for Acute LMCA - LAD Dissection due to Blunt Chest Trauma: A Case Study. Austin J Surg. 2017; 4(2): 1100. 

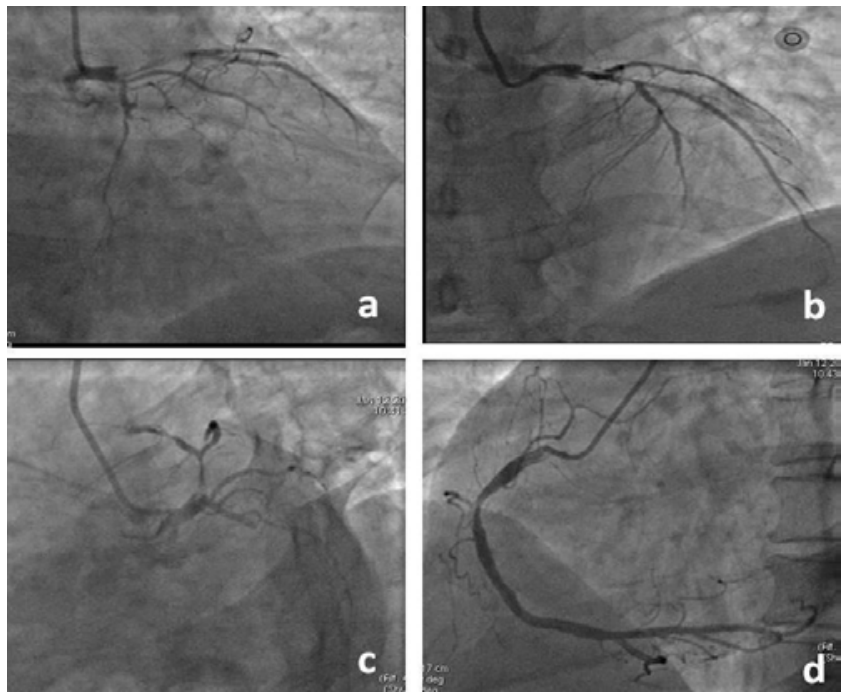

Figure 2: Coronary angiogram showing Acute Left main coronary artery (LMCA) Left Anterior Descending artery (LAD) dissection.

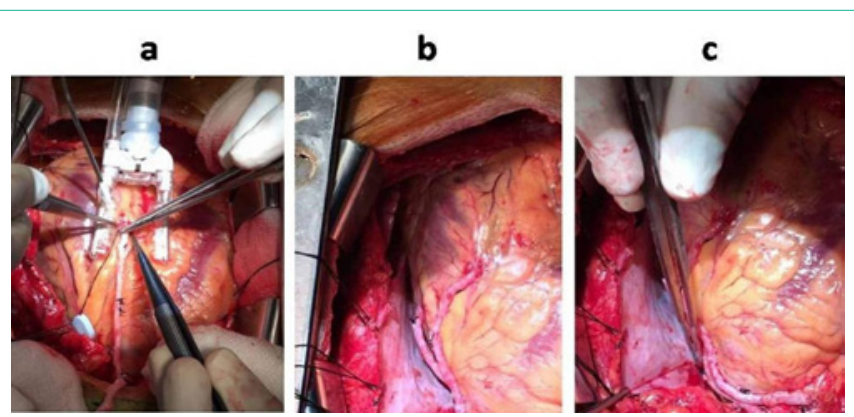

Figure 3: a) $L A D$ vein graft. b,c) Completed $L A D$ and diagonal vein grafts.

post operative day as his hemodynamic status became stable.

The patient was treated conservatively in consultation with the Neurologist/Neurosurgeon for the SDH. Repeat CT was done which showed no increase in size of SDH. Fracture right femur shaft was initially managed with skin traction followed by interlocking nailing of right femur subsequently. He was extubated only on the 6th post operative day because of the thyroid laminar fracture and compromised airway. Chest drains were removed the next day. Post operative echo-cardiogram showed normal chamber dimensions, Regional Wall Motion Abnormalities (RWMA), severe LV systolic dysfunction, LVEF: 25\%-30\%, sclerotic aortic valve, no AS, trivial AR/MR/TR, no Pulmonary Artery Hypertension (PAH), no clots or pericardial effusion, normal aortic arch. Eyelet wiring and bone plating with inter-maxillary fixation was done for fracture mandibleright side ramus and left side sub-condylar region. He improved gradually and was shifted to the room. Ryle's tube feeding was initiated and he started taking liquids orally with straw.

\section{Discussion}

ST-T segment elevation changes in electrocardiogram commonly represent myocardial contusion. However, coronary artery spasm, thrombosis, dissection of the aorta with propagation to the coronary arteries, or coronary artery dissection can cause significant ST-T segment elevation changes [3]. Acute traumatic dissection of a coronary artery after blunt thoracic trauma is extremely rare $[4,5]$. The LAD is involved in the majority of the cases followed by the right, circumflex, and left main coronary arteries [3]. The diagnosis is missed quite often or delayed, and at times it is postmortem finding.

Treatment approaches for acute coronary artery dissection after blunt chest trauma includes thrombolytic therapy, percutaneous intervention, and on-pump coronary artery bypass grafting and offpump coronary artery bypass grafting [2]. Although percutaneous intervention requires aggressive anti-platelet therapy, it is still an attractive approach in the setting of acute trauma because it provides rapid revascularization of the injured vessel and is minimally invasive [3]. Our patient had SDH and extensive limb, mandible \& thyroid laminar injuries, anti-platelets were not considered [6].

On-pump coronary artery bypass grafting requires systemic anticoagulation using high dose heparin. This increases the risk of bleeding from the operation site and from the injured organs in the setting of acute multiple trauma. Cardiopulmonary bypass associated coagulopathy is another complication of on-pump coronary artery bypass grafting.

Exposure to cardiopulmonary bypass in the setting of multiple traumas may aggravate organ dysfunction, particularly increasing the risk of pulmonary, renal, and neurologic complications. Avoiding the cardiopulmonary bypass has been shown to reduce postoperative coagulopathy and blood transfusions, renal complications, and possibly improve neurologic outcomes [7]. Off-pump coronary artery bypass operations have promising clinical outcomes [8]. The $\mathrm{OPCAB}$ approach was indeed found to be most effective in high-risk patients [8].

LMCA-LAD dissection in our patient was an acute emergency. Due to multiple associated injuries and severe head injury the patient was not amenable for angioplasty, which directed us to perform emergency off-pump coronary artery bypass grafting.

\section{Conclusion}

OPCAB operation is a safe and effective technique for the management of acute dissection of a coronary artery after blunt chest trauma. Off-pump coronary artery bypass grafting should strongly be considered when percutaneous intervention cannot be done for revascularization.

\section{References}

1. Jason D Adler, Thomas M. Scalea. Right coronary artery dissection after blunt chest trauma. Injury Extra. 2010; 41: 77-79.

2. Korach CT, Hunter HL, Lazar RJ, Shemin OM, Shapira. OPCAB for acute LAD dissection due to blunt chest trauma. Ann Thorac Surg. 2006; 82: 312314.

3. Ginzburg E, Dygert J, Parra-Davila E, Lynn M, Almedia J, Mayor M. Coronary artery stenting for occlusive dissection after blunt chest trauma. J Trauma. 1988; 45: 157-161.

4. Sun L, Li Z, Zhao Y, Han J, Henein MY. Left anterior descending artery occlusion secondary to blunt chest trauma diagnosed by comprehensive echocardiography and coronary angiography. J Clin Ultrasound. 2012; 40: 370-374.

5. Moore FO, Berne JD, Turner WF, Villarreal DH, McGovern T, Rowe SA et al. Off-pump coronary artery bypass is an alternative to conventional 
cardiopulmonary bypass when repair of traumatic coronary artery injuries is indicated. Am Surg. 2007; 73: 296-298.

6. Beynon C, Hertle DN, Unterberg AW, Sakowitz OW. Clinical review: Traumatic brain injury in patients receiving antiplatelet medication. Critical Care. 2012; 16: 228.

7. Al-Ruzzeh S, Nakamara K, Athanasiou T, Modine T, George S, Yacoub M et al. Does Off pump Coronary Artery Bypass (OPCAB) surgery improve the outcome in high-risk patients? A comparative study of 1398 high-risk patients. Eur J Cardiothorac Surg. 2003; 23: 50-55.

8. Sabik JF, Blackstone EH, Lytle BW, Houghtaling PL, Gillinov AM, Cosgrove $\mathrm{DM}$. Equivalent midterm outcomes after off pump and on-pump coronary surgery. J Thorac Cardiovasc Surg. 2004; 127: 142-148.
Austin J Surg - Volume 4 Issue 2 - 2017

ISSN : 2381-9030 | www.austinpublishing group.com

Jalal et al. () All rights are reserved
Citation: Gopal R, Nebhu MS, Mohamed AA and Jalal MJA. Off-Pump Coronary Artery Bypass (OPCAB) for Acute LMCA - LAD Dissection due to Blunt Chest Trauma: A Case Study. Austin J Surg. 2017; 4(2): 1100. 